\title{
The role and improvement of technical services in agriculture
}

\author{
Galia Kokieva ${ }^{1,}{ }^{*}$, Konstantin Krivoshapkin ${ }^{1}$, Yrii Dondokov ${ }^{1,2}$, Maria Evseeva ${ }^{1}$, and Alexei \\ Stroyev $^{1}$ \\ ${ }^{1}$ The Arctic State Agrotechnological University, 3, sh. Sergelyakhskoe $3 \mathrm{~km}, 677007$, Yakutsk, the \\ Republic of Sakha (Yakutia), Russia \\ ${ }^{2}$ The North-Eastern Federal University named after M.K. Ammosov, 58, st.Belinskogo, 677007, \\ Yakutsk, the Republic of Sakha (Yakutia), Russia
}

\begin{abstract}
The accelerated development of technical service is a natural manifestation of a common strategy of modern industrial production. Scientific research and practice indicate that the need for machines in maintenance and repair is an objective reality. This features of modern techniques, the conditions for its operation. The importance of development and improvement of repair and service production is to provide resource saving agricultural machinery. With a continued trend towards ensuring the equalization of components of the technical product, it is mainly used in the principle of replacing or restoring elements during operation. The article describes the technical operation of the machine and tractor fleet. It is noted that for the full functioning of the technique it is necessary to diagnose in a timely manner, then the need is running and running on the need. If you compare the overall generation of tractors in conditional hectares and planning funds to pay for labor, it is necessary to proceed from the costs of time costs for the conditional hectare of tractortransport work, taking into account. Using the indicator of normosmen, we can comprehensively assess the effectiveness of the use of techniques for information for intra-economic planning and managing the work of the machine-tractor fleet.
\end{abstract}

\section{Introduction}

The world experience of operating agricultural machinery indicates that even the most advanced car can implement their potential opportunities only under the condition of organized technical service. In a number of suggestion for the improvement of material and technical provisions of the technique and the provision of technical assistance in the maintenance of equipment and the warranty period, a special place is given to the creation of a dealer network as a mediation structure. But such structures cannot develop everywhere. The crushing of large collective farms into small, as well as the organization of peasant farms led to an increase in the need for various techniques, which is not or it is due to the high costs today inaccessible for almost everyone. The need for maintenance and

*Corresponding author: kokievagalia@mail.ru 
repair-characteristic property of belt technology, due to the presence in the machines of replaced short-lived structural elements and short-lived non-constructive elements. This implies the need for a special form of production-repairs.

In recent years, the level of technical operation and repair of agricultural equipment has significantly increased. A lot of work in this direction is conducted in research and design institutions. The engineer is developing the most rational schemes of power supply and automation of rural areas, propose activities that increase reliability, design various automatic devices controlling electrical stations and networks and protect them. The technical diagnosis of rolling bearings is becoming more and more important in the operation and repair of tractors, cars, complex agricultural equipment due to the fact that the bearing failure leads, as a rule, to serious breakdowns and further to high costs and loss of time during repair. As a result of the operation of technical diagnostics (STD) of tractors, the greatest effect can be obtained when using electrical measurement methods using electronic equipment, having significant advantages over mechanical and electrical measuring diagnostic devices. When diagnosing the components of the components (elements) of the machines, the direct or indirect measurement of the parameters of the state is accompanied by the measurement error due to the limited accuracy of the methods and diagnostic methods used.

The high quality of the engines is largely due to the correct acquisition of parts. When performing small dispersed volumes of work, difficult to mechanization, you have to use unproductive manual work. This refers to the enlighted, planning earthworks in the construction and repair of engineering communications, sealing of soils of backfill in trenches, sinuses of foundations, wells, etc., drilling and installation work, lifting and moving goods, to the current repair of road surfaces. Meanwhile, the problem of improving the efficiency of machines and means of mechanization in construction is closely related to the increase in their technical and operational performance. The low level of frequent impact pulses serves as an objective criterion of a normal working condition, while high indicates a malfunction of bearings due to poor installation, lubricant insufficiency, damage to the components of the bearing, etc. The impact pulse method allows you to detect defects on new or newly mounted bearings. Constantly controlling the frequency of impact pulses, you can monitor the change in the technical condition and detect damage to the bearings in the early stages. This makes it possible to plan the replacement of bearings in advance. The high quality of the engines is largely due to the correct acquisition of parts. It is achieved by the use of the earning additives to the air, fuel and lubricating oil supplied in them, and the change in the modes and the condition of the rolling-on-perts, the speed of the crankshaft, the duration of the modes, water temperature, oil.

\section{Content}

A characteristic and very significant feature of the modern stage of agricultural development is the versatile use of automation tools. Automation is increasingly crucial for increasing the productivity of both stationary and mobile agricultural units, for improving product quality, facilitating working conditions, and improving production culture [2-4].

As a result of the operation of technical diagnostic tools (STD) of tractors, the greatest effect can be obtained when using electrical measurement methods using electronic equipment, which have significant advantages over mechanical and electrical measuring diagnostic devices: speed, the ability to control fast-flowing (dynamic) working processes in systems and mechanisms, ensuring simultaneous control of a set of parameters of the technical condition of units, the ability to automate the diagnostic process, etc. Table 1 shows the main methods of diagnosing tractor components using electronic means of 
diagnosing tractors, which are divided into diagnostics by functional and resource parameters $[10,12,15]$.

Table 1. Functional and resource indicators.

\begin{tabular}{|c|l|}
\hline No & \multicolumn{1}{|c|}{ Functional and resource indicators } \\
\hline 1 & $\begin{array}{l}\text { Diesel engine diagnostics based on the parameters of working processes, based on obtaining } \\
\text { information about changes in these parameters (fuel supply, lubrication, combustion, gas } \\
\text { exchange), depending on the state of adjustments and wear of the interfaces of the engine } \\
\text { assembly units; }\end{array}$ \\
\hline 2 & $\begin{array}{l}\text { Diesel engine diagnostics based on transient parameters, which uses information about } \\
\text { unsteady operating modes of the object }\end{array}$ \\
\hline 3 & $\begin{array}{l}\text { Thermal, based on the measurement of the temperature of water, oil, engine exhaust gases, } \\
\text { surface temperature of housing parts; }\end{array}$ \\
\hline 4 & Spectrographic, used in the analysis of waste oil samples to determine wear products \\
\hline
\end{tabular}

Transport links between these contributions are presented with distances and conditions of movement of machines, their speed, maneuverability and other factors.

Replaceable operational performance of the machine is determined by the expression $[1,5]:$

$$
\Pi_{s m}=\frac{V_{s m}}{t_{s m}}
$$

where $\mathrm{V}_{\mathrm{sm}}$-is the amount of work performed during the shift; $\mathrm{t}_{\mathrm{Sm}}$ - changeable time.

Taking into account the dispersal of objects, the work performed per shift:

$$
V_{s m}=\sum_{i=1}^{n} V_{i},
$$

where $\mathrm{V}_{\mathrm{i}}$-is the scope of work on the $\mathrm{i}$-volume subjection; $\mathrm{n}$ - the number of subline.

Changeable time $T_{S m}$, in turn, consists of time $T_{0}$ mileage of the machine from the mechanization database to the object at the beginning of the work shift and back at the end of the shift, time $T_{p}$ work on the object and time $T_{\text {per }}$ movements from one object to another

$$
t_{s m}=t_{0}+t_{\mathrm{p}}+t_{\text {per }}
$$

Mileage time from the base of mechanization to the object and back:

$$
t_{0}=\frac{l_{0}}{v},
$$

where $l_{0}=l_{01}+l_{02}$ - is the total distribution from the base of mechanization to the first subline and from the last sub-section about the mechanization base; $v$ - The average transport velocity of the base machine. Operating time:

$$
t_{\mathrm{p}}=\frac{V_{s m}}{P_{\text {exs }}},
$$

where $P_{\text {exs }}-$ is operational performance;

$P_{\text {exs }}=\Pi_{\text {tex }} k_{v} ; P_{\text {tex }}-$ technical productivity; $k_{v}$ - The coefficient of use of the machine in time during the working cycle. Time to move the machine from one subline to another:

$$
t_{p e r}=\frac{\sum_{i=1}^{n-1} l_{i}}{v}
$$

where $l_{i}-$ the distance between $i_{\text {tim }} \mathrm{I}+1$-inclines. In general.

In general: 


$$
t_{s m}=\frac{l_{0}+\sum_{i=1}^{n-1} l_{i}}{v}+\frac{V_{s m}}{P_{\text {exs }}} .
$$

Giventhat $v t_{s m}=l_{\max }-$ is the maximum possible mileage during the shift, the last expression is represented as:

$$
k_{v s m}^{\prime}=\frac{\Pi_{s m}}{\Pi_{e x c}}=1-\frac{l_{0}+\sum_{i=1}^{n-1} l_{i}}{l_{\max }} \leq 1,
$$

where $k_{v s m}^{\prime}$ - theoretical utility utilization coefficient in time during the shift.

The shift rate is used to determine the amount of earnings of machine operators. Meanwhile, this indicator can also be used to characterize the intensity of tractor use in the economy [7,13]. The output of tractors in normosmencan also be expressed in energy consumption. To do this, it is necessary to determine the average energy rating of the normosmen for the zones, make tables of coefficients and multiply the corresponding indicators of the use of the tractor fleet by them. It is more difficult to apply standard changes when planning the work of the machine and tractor fleet. It is very difficult to foresee in advance what proportion of the work will be done by this or that unit. To avoid this difficulty, it can be assumed that each job employs one average unit, the norm shift of which is equal to the weighted average shift rate of the production of real units $[6,8,14]$ :

$$
W^{\prime}=\frac{\sum_{i=1}^{k} W_{i} n_{i}}{\sum_{i=1}^{k} n_{i}},
$$

where $W^{\prime}$ и $W_{i}-$ Nosmosmmeman of the middle and the $\mathrm{i}$-th aggregate; $\mathrm{n}_{-} \mathrm{i}$ - the number of $\mathrm{i}-\mathrm{x}$ units; $\mathrm{K}$ is the total number of units performing the same operation.

Having a table of norm changes of averaged units, you can use it to estimate the composition of the machine and tractor fleet. The best shouldbeconsidered the composition of the fleet, in which the normosmena of the average unit will be the maximum. An increase in the normosmenacanbe achieved by choosing more productive units for a particular operation $[9,11]$. The table of norm changes of averaged aggregates can replace the table of coefficients of conversion of works to hectares of soft plowing when calculating the volume of mechanized work on the cultivation of agricultural crops.

For a single unit:

$$
A=\frac{q}{W^{\prime}} S
$$

for a group of aggregates:

$$
A=\frac{q(n+1)}{W_{\text {г.a. }}^{\prime}} S,
$$

where $A$ - scope of work in Nimosmnahs; $q$ - the number of processing repetitions; $W^{\prime}$ и $W_{\text {г.а. }}^{\prime}$ - being processed; $\mathrm{n}$ is the number of serving head unit or tractors served by him.; $S$ - processed area; $\mathrm{n}$ is the number of serving head unit or tractors served by him.

Having determined the volume of mechanized work in Nimosmmen on the hectare of cultivated land in the period of the agricultural year,it is possible to make a mathematical model for loading a machine-tractor fleet in poorerity:

$$
\sum a_{i j} S_{i}=b_{j},
$$

where $a_{i j}$ - the amount of mechanized work per hectare of the i-th crop in the $\mathrm{j}$-th period; $\mathrm{S} \mathrm{i}$ - the area occupied by the $\mathrm{i}$-th crop; bj - the total amount of work in the $\mathrm{j}$-th period.

The amount of mechanized work per hectare of the $\mathrm{i}$-th crop in the $\mathrm{j}$-th period; $\mathrm{Si}-$ the area occupied by the i-th crop; $\mathrm{bj}$ - the total amount of work in the $\mathrm{j}$-th period. 
A more accurate presentation about the uneven loading of the machine-tractor park during the year can be obtained by determining the decade-long tension of its work

$$
m_{j}=\frac{b_{j}}{t}
$$

wheret - duration of the $\mathrm{j}$-th period in decades.

Taking advantage of the decadane tension of the work, you can withdraw the formula to determine the required number of tractors. To do this, you need to know the decadane performance of one tractor. The number of replaceable standards made by the tractor in the decade depends on the number of spent days (shifts) and the performance of the output rate for each shift. This dependence can be written as a work:

$$
10 k_{\mathrm{Bp}} k_{\mathrm{cm}} k_{\mathrm{H}} \text {, }
$$

where $k_{\mathrm{Bp}}$ - calendar utilization rate defined by the number of working days in decade; $k_{\text {см }}$ - replacement coefficient; $k_{\mathrm{H}}$ - The performance indicator of replacement standards of production, equal to the ratio of the number of interchangeable norms to the number of waste shifts. The number of tractors needed to perform work in the $\mathrm{j}$-th period will be:

$$
N_{j}=\frac{0,1 m_{j}}{k_{\mathrm{Bp}} k_{\mathrm{cM}} k_{\mathrm{H}}} .
$$

Table 2 shows the values included in formula 14.

Table 2. The values of the values of the replaceable norms made by the tractor in the decade.

\begin{tabular}{|l|c|c|c|c|c|}
\hline Working period & $\boldsymbol{m}_{\boldsymbol{j}}$ & $\boldsymbol{k}_{\boldsymbol{v} \boldsymbol{p}}$ & $\boldsymbol{k}_{\boldsymbol{s m}}$ & $\boldsymbol{k}_{\mathrm{H}}$ & $\boldsymbol{N}_{\boldsymbol{j}}$ \\
\hline Spring & 172 & 0.98 & 1.90 & 0.80 & 12 \\
\hline summery & 61 & 0.56 & 1.63 & 0.82 & 7 \\
\hline Summer-autumn & 96 & 0.50 & 1.60 & 0.88 & 14 \\
\hline autumn & 78 & 0.53 & 1.90 & 0.91 & 9 \\
\hline Winter & 39 & 0.40 & 1.00 & 0.96 & 10 \\
\hline Peryear & - & 0.43 & 1.43 & 0.87 & - \\
\hline
\end{tabular}

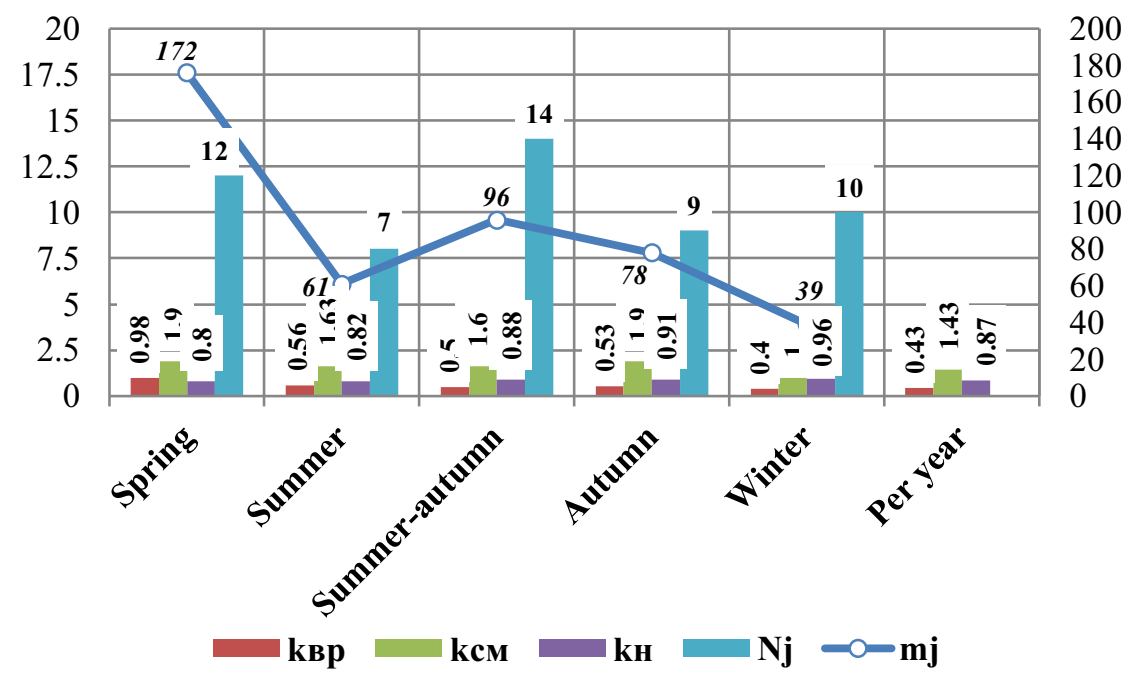

Fig. 1.The number of replaceable rules made by the tractor in a decade, depending on the number of spent days (shift) and the performance of the implementation rate for each shift. 
The total need for tractors is determined by the maximum value of $N_{j}$. In our example $\mathrm{n} N_{j}$.days of the summer-autumn period. In fact, 15 tractors were used in the collective farm, which closely coincides with the results of the calculation. A rational way to restore parts is currently chosen by a technical and economic criterion defined as the ratio of either the cost of the development or the durability ratio or the costs of the same indicators. More effective is the one that provides the minimum value of this criterion. Even more, they occupy consumers operating machines organizing their maintenance and repair. This is explained by the fact that, unlike the old slurry machines with a large margin of strength in modern machines, structural parts are used and non-constructive assembly adjustment of the color lubricant and other elements calculated for various duration of work and periodically requiring replacement or renewal. These data allow you to identify the approximate composition of the tractor fleet. In the summer-autumn period, the total number of tractors is established, the minimum number of tractors in the park is determined on the summer period. Replaceable production rate, as a unit of measurement of work and their cost, is used in the preparation of technological maps. It also serves as the main indicator in the operational planning of the machine-tractor fleet.

\section{Conclusion}

In the conditions of a market economy, the main and decisive provision of progress in the system of technical service should be the priority of the commodity producer. At the same time, an exception should be achieved over demand for cars, equipment and services, the free right to acquire technical means, choose the performer of work and services. Mutual economic interest and complete freedom of the relationship involved in this part may become predominant. At the heart of the technical service system on the village in the new conditions, the maintenance of the repair and service base, the economic interest and legal responsibility of manufacturers and dealers for the material and technical support of the consumer, the constant readiness of the machines to work, the priority of the manufacturer of agricultural products. All this requires scientific research and substantiation of the optimal structure of the repair and service base in the conditions of economic reform and market relations.

\section{References}

1. A.S. Denisov, E.V. Feklin, Scientific life, 15, 965-979 (2020) doi: 10.35679/19919476-2020-15-7-965-979

2. Y.Y. Gazizyanova, T.G. Lazareva, Bulletin of Eurasian Science,11 (2), 14 (2019)

3. V.V. Glushchenko, Mechanical Engineering Bulletin, 8, 82-88 (2020) doi: 10.36652/0042-4633-2020-8-82-88

4. R.A. Kasymbekov, Y.D. Osmonov, B.S. Sultanaliev, S.Z. Akmatova, M.S.Volkhonov, M.A. Ivanova, Agrarian Bulletin of the Upper Volga, 2 (31), 85-94 (2020)

5. I.L. Kovalev, Agricultural machinery: maintenance and repair, 3, 44-53(2017)

6. I.L. Kovalev, Resources and Technology, 14 (2), 12-25 (2017)

7. T.I. Kruzhkova, O.A. Ruschitskaya, K.P. Stozhko, D.K. Stozhko, Agrarian Bulletin of the Urals, S13, 46-53 (2020) doi: 10.32417/1997-4868-2021-13-46-53 
8. L.I. Kushnarev, Technical and economic assessment of domestic and foreign technology (2013)

9. A.V. Mineev, Youth and Science, 5, 25 (2017)

10. Z.N. Mishina, Technical service of machines, 3 (140), 49-56 (2020)

11. V.A. Nepochatenko, A.V. Nepochatenko, Economics and management of the agroindustrial complex, 9, 9-12 (2012)

12. S.L. Nikitchenko, A.V. Kotovich, Collection of articles of the 11th International Scientific and Practical Conference in the framework of the 21st International Agroindustrial Exhibition "Interagromash-2018", 195-198 (2018)

13. S.N. Shukhanov, A.V. Kuzmin, P.A. Boloev, Engineering technologies and systems, 30 (1), 8-20 (2020) doi: 10.15507/2658-4123.030.202001.008-020

14. N.V. Stepanov, S.N. Shukhanov, Tractors and agricultural machinery, 4, 80-84 (2019) doi: 10.31992/0321-4443-2019-4-80-84

15. I.A. Uspensky, G.D. Kokorev, I.A. Yukhin, V.A. Shaforostov, Increasing the efficiency of harvesting and transport operations in the agro-industrial complex on the example of pome crops, 4 (40), 148-154 (2018) 